\title{
A formação da ALCA e os prováveis efeitos sobre as exportações agrícolas brasileiras ${ }^{*}$
}

Márcia Batista da Fonsêca** Álvaro Barrantes Hidalgo***

Resumo: Na última década do século XX, os principais empreendimentos de integração com que o Brasil se envolveu foram o Mercado Comum do Sul (MERCOSUL) e as negociações em torno da formação da Área de Livre Comércio das Américas (ALCA). A integração regional junto com a liberalização comercial beneficiou profundamente o setor agrícola brasileiro e hoje o país apresenta-se no cenário da ALCA como o segundo maior exportador de produtos agrícolas do bloco. Os efeitos provocados sobre o comércio estão relacionados diretamente às restrições comerciais antes impostas aos parceiros e ao volume de comércio inicialmente verificado entre esses países. Tendo em vista esse aspecto, o objetivo deste estudo é o de conhecer os prováveis efeitos da participação do Brasil na ALCA no que diz respeito às exportações de café, cacau, soja, açúcar, suco de laranja e carnes no período 1999-2002. Essa análise é feita sob a ótica do equilíbrio parcial, desenvolvido por Laird e Yeats (1986) para estimar os efeitos de primeira ordem, ou seja, as reduções das restrições comerciais através da abordagem das elasticidades. A conclusão a que

\footnotetext{
*Os autores agradecem os comentários e sugestões valiosas recebidas dos pareceristas anônimos desta revista, isentando-os de quaisquer erros e omissões remanescentes.

**Doutora em Economia pelo PIMES - UFPE, Professora de Economia do Departamento de Economia e do Curso de Pós Graduação em Economia da UFPB. mb_marcia@hotmail.com

***Doutor em Economia pelo IPE - Universidade de São Paulo, Professor de Economia do Departamento de Economia e do Curso de Pós Graduação em Economia da UFPE, Membro do Colegiado do PPGE - UFPE e Pesquisador do CNPq. hidalgo@ufpe.br
} 
se pode chegar com relação às simulações feitas para o período 19992002, com a liberalização total das restrições comerciais impostas pelos países membros da ALCA às exportações brasileiras, é que para o grupo de produtos estudados, o efeito criação de comércio mostra-se superior ao efeito desvio de comércio, tornando evidente a competitividade do agronegócio brasileiro dentro da ALCA.

Palavras-chave: Exportações agrícolas, Integração Regional, ALCA.

\section{Classificação JEL: F15 e Q17}

Abstract: In the last decade of the 20th century, the main enterprises of integration in which Brazil was involved were MERCOSUR (Common Market of the South America) and the negotiations about the formation of FTAA (Free Trade Area of the Americas). The regional integration together with the trade liberalization has deeply benefited the Brazilian agricultural sector, and nowadays the country is ranked as the second biggest agricultural product exporter country inside the FTAA. The effects on commerce are directly related to the trade restrictions once imposed on partners and on trade volume initially verified among these countries. Considering this aspect, the goal of this study is to recognize the probable effects of Brazil's participation in FTAA in what refers to coffee, cacao, soy, sugar, orange juice and meat exports in the period of 1999-2002. This analysis was performed under the optics of the partial equilibrium that was developed by Laird and Yeats (1986), so that, to estimate the effects of first order, i.e. the reductions in the trade restrictions using the elasticities approach. The conclusion made in relation to the simulations that have been made to the period of 1999-2002, with total liberation from trade restrictions imposed by FTAA's country members to the Brazilian exports, is that, for the group of products studied, the trade creation effect turns out to be superior to the trade diversion one, showing clearly the competitiveness of Brazilian agribusiness inside FTAA.

Keywords: Agricultural export, Regional integration, FTTA.

JEL Classification: F15, Q17 


\section{Introdução}

As negociações formais em torno da formação da ALCA tiveram início na década de 90 , e até o momento foram realizadas nove reuniões ministeriais para a consecução desse projeto, na qual se eliminarão progressivamente as barreiras ao comércio e ao investimento esperando-se concluir as respectivas negociações até o ano de 2005.

Segundo dados da Organização Mundial de Comércio (OMC), de 2004, essa região representa um mercado potencial de cerca de 850 milhões de pessoas com um Produto Interno Bruto (PIB) de aproximadamente US \$12,5 trilhões, além da garantia de acesso preferencial a mercados desenvolvidos por parte de países menores.

Particularizando o setor agrícola, os dados da OMC (2004) revelam que os países que formarão a ALCA compreendem 25,8\% da área agrícola mundial e as exportações agrícolas totais do bloco estão próximas dos US\$ 200 bilhões, representando perto de $35 \%$ das exportações totais do planeta. A ALCA aparece como um bloco que gera grandes excedentes agrícolas. Na região são produzidos 37,4\% da produção mundial de café e $15 \%$ da produção de açúcar, cereais e oleaginosas.

O Brasil tem grande importância nesse cenário, sendo o segundo maior exportador de produtos agrícolas da ALCA. Segundo dados do Ministério do Desenvolvimento Indústria e Comércio e da Secretaria de Comércio Exterior, (MDIC/SECEX) (2004), aproximadamente 41,15\% das exportações totais do Brasil em 2004 foram constituídas de produtos agrícolas e os EUA constituem o maior parceiro comercial do Brasil, seguido de União Européia e países da Ásia.

Abreu (2001) argumenta que as preocupações brasileiras quanto às negociações da ALCA podem ser assim resumidas: distribuição temporal das concessões recíprocas referentes a acesso, especialmente no caso do mercado de bens; garantia de inclusão de temas de especial interesse brasileiro, em particular legislação antidumping, meio ambiente e subsídios agrícolas, para que estes não sirvam de base para o uso de instrumentos adicionais de proteção, especialmente nos EUA.

Assumindo-se que a produção agrícola brasileira dos principais produtos da pauta de exportação é competitiva entre os países que formam a ALCA, um aumento no volume das exportações agrícolas do Brasil para 
seus parceiros após a desgravação tarifária implicaria redução dos preços dentro dos mercados compradores, e a substituição por um comprador eficiente evidenciaria criação de comércio para esses produtos.

Assim, com base em tal hipótese e ainda, diante da relevância da negociação da Área de Livre Comércio das Américas para a economia brasileira e da relativa escassez de estudos empíricos a respeito dos impactos potenciais do acordo, este trabalho tem como objetivo principal analisar os prováveis efeitos da participação do Brasil na ALCA, no que se refere aos principais produtos agrícolas brasileiros exportáveis ${ }^{1}$ de 1999 a 2002 e observar se existirão ganhos de comércio devido à integração.

A análise será feita com base nas equações do modelo de equilíbrio parcial de Laird e Yeats (1986) que permitem calcular a criação e o desvio de comércio que ocorreriam a partir de uma redução tarifária preferencial, concedida em concomitância pelos países membros de um acordo comercial. A importância desse tipo de estudo reside no fato de que se pode obter ex-ante, indicações a respeito do setor em análise, ou seja, se este deve merecer maior ou menor atenção do governo brasileiro no momento das negociações comerciais, dado o seu potencial de crescimento em relação aos países membros do bloco. Após esta introdução, o trabalho apresenta na seção 2 uma descrição do setor agrícola e o protecionismo americano sobre as exportações brasileiras; na seção 3 encontra-se a descrição da metodologia de cálculo da criação e do desvio de comércio; e na seção 4 são apresentadas as conclusões do trabalho.

\section{A ALCA, o setor agrícola e o protecionismo americano sobre as exportações agrícolas brasileiras}

Com a "Rodada Uruguai" do GATT, o setor agrícola passou a fazer parte da pauta de negociações e com o Acordo de Marrakech (1994), as discussões resultaram no compromisso de redução por parte dos países

\footnotetext{
${ }^{1}$ Os produtos selecionados para serem analisados foram: açúcar, café, soja, carnes, cacau e suco de laranja. O motivo para essa escolha está relacionado à importância desses produtos na pauta de exportações brasileira. Entre 1999-2002, em conjunto esses produtos corresponderam a aproximadamente $85 \%$ da pauta de exportações agrícolas. Por outro lado, a escolha do período 1999-2002 reflete a intensificação das negociações para a formação da ALCA.
} 
desenvolvidos, das distorções nesses mercados. Além disso, no que diz respeito às barreiras não tarifárias ao comércio, foram firmados o "Acordo sobre Barreiras Técnicas ao Comércio" (TBT) e o "Acordo das Medidas Sanitárias e Fitossanitárias” (SPS) com objetivo de harmonizar as normas e regras as quais tratam da proteção ao meio ambiente, à saúde pública e ao bem-estar dos consumidores.

Na $4^{a}$ Reunião Ministerial sobre o comércio realizada em São José, Costa Rica, em 19/03/1998 foram discutidos os primeiros acertos sobre o setor agrícola na ALCA, ficando acordado entre os países membros que as negociações da ALCA nessa área seriam voltadas para facilitar o comércio sendo respeitadas as disposições da OMC sobre o assunto, como também seriam objetivos dos países membros: a) Eliminar todos os subsídios às exportações agrícolas os quais afetassem o comércio no hemisfério; b) Assegurar que medidas sanitárias e fitossanitárias não fossem usadas como barreiras ao comércio; c) Práticas que distorcem o comércio de produtos agrícolas deveriam ser reprimidas.

Todas essas preocupações foram mantidas na Minuta do Acordo da ALCA (julho de 2001), revelando a importância do setor agroexportador para os países membros do acordo. Porém, na reunião ministerial realizada em novembro de 2003 em Miami, EUA, ficou decidido que a eliminação dos apoios internos concedidos pelos EUA à produção e às exportações agropecuárias não entrariam na negociação. Os EUA querem que o assunto seja tratado primeiro na OMC. O Brasil defende que a manutenção dos subsídios norte-americanos deve ser compensada via acesso a mercados de produtos agropecuários a todos os países do bloco.

As discussões acerca da participação do Brasil na ALCA têm sido lentas e graduais, com o Brasil utilizando-se da "postura do não-engajamento" devido principalmente ao protecionismo implícito dos EUA à sua produção doméstica. Embora a tarifa média dos EUA seja muito baixa, os picos tarifários, as quotas tarifárias e as barreiras não-tarifárias tornam o mercado norte americano extremamente protegido no caso dos diversos produtos agrícolas e também insumos industriais. A tarifa média brasileira, ainda que significativamente mais alta que a dos Estados Unidos, retrata com maior precisão a real proteção de que goza a indústria doméstica frente às importações.

Segundo dados da Embaixada Brasileira em Washington (2002), o 
açúcar brasileiro exportado para os Estados Unidos sofre um pico tarifário de US\$338,7 por tonelada acima da cota, já para o suco de laranja o pico é de US\$ 0,785 por litro. Além disso, carnes e óleo de soja são produtos agrícolas brasileiros sobre os quais incidem exigências importantes de cumprimento de normas técnicas.

Os EUA são o maior importador de produtos agrícolas brasileiros dentro da ALCA. As importações de açúcar brasileiro feitas pelo mercado norte-americano obedecem ao sistema de cotas. Além disso, o Brasil não recebe isenção tarifária no âmbito do "Sistema Geral de Preferências” (SGP) do qual o país faz parte, nem tão pouco é beneficiado nas exportações dentro da cota. O governo americano alega que o Brasil possui vantagem comparativa na produção do açúcar e, portanto, não pode ser beneficiado com o SGP. Por outro lado, o governo americano subsidia a produção de açúcar de beterraba e os adoçantes produzidos a partir do milho, os quais são os maiores beneficiários do sistema de cotas.

No caso do suco de laranja, os EUA concedem isenção tarifária para os exportadores do produto no âmbito do NAFTA. Entretanto, as exportações de suco de laranja brasileiro para o Estado da Flórida são oneradas com uma taxa de equalização de US $\$ 0,27$ por galão. Ademais, o governo americano abriu um processo em 04/06/1986, decidido preliminarmente em 23/10/1986 e definitivamente julgado em 12/05/1998, resultando em uma imposição de um direito definitivo antidumping de $0 \%$ a $2,52 \%$ sobre as importações do produto brasileiro.

Os EUA, maiores produtores mundiais de soja, produzem a soja com um elevado grau de proteção, o que representa uma barreira comercial para as exportações brasileiras. Segundo Tavares (2002), o Brasil produz soja com um custo de produção em torno de $40 \%$ inferior aos EUA, com produtividade superior em quase $20 \%$ e com uma rentabilidade acima da americana, mas as exportações para os EUA são ainda insignificantes devido às barreiras comerciais impostas pelos norte-americanos. Na cadeia produtiva do complexo da soja, enquanto que o grão e o farelo sofrem pequenas taxações, o óleo de soja é taxado em $20,8 \%$.

A mais recente lei agrícola americana aprovada em 2002, a Farm Bill, intensificou a volta mais que declarada ao protecionismo. Essa lei 
oferece mais de doze programas relacionados com o comércio exterior de produtos agrícolas. O governo americano autorizou mais de US\$ 108 bilhões entre 2002 e 2007 em subsídios para os produtores agrícolas.

Nas reuniões da ALCA, em Quito (2002) e em Miami (2003), ficou estabelecido um consenso sobre a eliminação dos subsídios às exportações agrícolas intrabloco, dentro da ALCA. Porém, os EUA defenderam a hipótese de reintrodução destes subsídios por parte de algum país membro, caso algum parceiro venha a realizar importações subsidiadas de países extrabloco.

Durante a reunião de Miami, o Brasil priorizou a negociação de um maior acesso aos mercados agrícolas com o objetivo de aumentar as cotas de exportações de açúcar para os EUA e a redução das tarifas que incidem sobre o suco de laranja no mercado norte-americano. Além disso, garantir a abertura dos mercados dos EUA, Canadá e México para o frango brasileiro, que é atingido duramente por barreiras nãotarifárias. Os EUA não importam carne brasileira bovina, suína e de frango in natura sob a alegação de doenças e diferenciadas formas de certificação.

As divergências geradas na reunião de Miami impediram a concretização da ALCA estipulada para 2004. Desse encontro surgiu a ALCA LIGHT, um acordo geral, com uma base comum aos 34 países e acordos de segunda geração, em que os países poderiam assumir níveis distintos de integração por meio de acordos bilaterais e/ou plurilaterais, quebrando a Cláusula da Nação mais Favorecida Regional, ou seja, permitindo-se a concessão de tratamento preferencial diferenciado dentro do bloco.

Na Reunião de Puebla (2004) voltou-se a discutir que o objetivo da ALCA seria tornar a oferta apresentada a um país válida para todos, podendo apenas conter diferentes ritmos e prazos de desgravação de acordo com o tratamento especial e diferenciado para economias menores. A reunião foi suspensa por falta de consenso sobre um conjunto comum, pois os EUA só aceitam discutir os subsídios agrícolas e a política antidumping na OMC.

O Brasil quer que o Acordo Agrícola da OMC seja cumprido e que sejam reduzidos os subsídios para a sua entrada na ALCA. A desgravação tarifária e a eliminação das barreiras não tarifárias representam uma forma de expansão das exportações brasileiras para os países membros. 


\section{Modelo Empírico: Metodologia e Cálculo da Criação e do Desvio de Comércio}

O processo de formação de um bloco comercial implica em dois efeitos: criação e desvio de comércio. A fim de calcular esses efeitos para o Brasil, no que diz respeito a sua participação na ALCA, este estudo utiliza-se da abordagem das elasticidades desenvolvida por Laird e Yeats (1986). A principal vantagem da utilização dessa abordagem é o pequeno volume de informações requerido, a saber, a demanda de importações, as tarifas, a elasticidade preço da demanda de importações e a elasticidade de substituição.

O modelo de Laird e Yeats parte de uma análise de equilíbrio parcial do bem-estar, usando funções de demanda de importações isoelásticas e que relacionam o total importado de um bem por um país com a renda real, o preço do bem importado e o preço do substituto doméstico medido na mesma moeda. Sabendo-se que os países j (importador) e k (exportador) pertencem a uma área de livre comércio, tem-se:

$$
\mathrm{m}_{\mathrm{ijk}}=\mathrm{f}\left(\mathrm{y}_{\mathrm{j}}, \mathrm{p}_{\mathrm{ijj}}, \mathrm{p}_{\mathrm{ijk}}\right)
$$

$\mathrm{m}_{\mathrm{ij} \mathrm{k}}$ é a função demanda de importações do país j pelo produto i proveniente do país $\mathrm{k}$; $\mathrm{y}_{\mathrm{j}}$ é a renda do país j; $\mathrm{p}_{\mathrm{ijj}}$ é o preço do bem i produzido e vendido no país importador $\mathrm{j}$, ou seja, o preço doméstico do bem i e $\mathrm{p}_{\mathrm{ijk}}$ é o preço do bem i vendido no país j, porém, produzido pelo país k.

A função oferta de exportações do país k para o país j do bem i é dada por:

$$
x_{i k j}=f\left(p_{i k j}\right)
$$

$\mathrm{X}_{\mathrm{ikj}}$ representa a função de oferta das exportações do país k para o país j do bem i; e $\mathrm{p}_{\mathrm{ikj}}$ é o preço do bem i produzido pelo país k e importado pelo país j.

No equilíbrio de mercado para o bem i, tem-se a igualdade entre a demanda de importações e a oferta de exportações:

$$
\mathrm{m}_{\mathrm{ijk}}=\mathrm{x}_{\mathrm{ikj}}
$$


Assume-se que o preço do bem i praticado no país j será igual ao preço recebido pelos exportadores do país $\mathrm{k}$, somadas às barreiras comerciais tarifárias e não-tarifárias, além dos custos com transporte e seguros. Supondo-se que sobre o bem i, importado do país $\mathrm{k}$, incida uma tarifa que englobe os componentes das barreiras comerciais, ou seja, um equivalente ad valorem ${ }^{2}$ cobrado pelo país j, tem-se:

$$
\mathrm{p}_{\mathrm{ijk}}=\mathrm{p}_{\mathrm{ikj}} \cdot\left(1+\mathrm{t}_{\mathrm{ijk}}\right)
$$

$\mathrm{t}_{\mathrm{ij} \mathrm{k}}$ é o nível tarifário inicial do bem i, dado por uma tarifa ad valorem, cobrada pelo país j na importação do bem i, proveniente do país $\mathrm{k}$.

Admitindo-se que o país j diminua suas barreiras de importação, esse efeito pode ser analisado com base no processo de derivação total do modelo. Após o processo de substituição das equações e admitindo que a elasticidade-oferta de exportações é infinita, é possível chegar à expressão para a criação de comércio $\left(\mathrm{TC}_{\mathrm{ijk}}\right)^{3}$.

$$
\mathrm{TC}_{\mathrm{ijk}}=\mathrm{m}_{\mathrm{ijk}} \cdot \varepsilon \mathrm{m}_{\mathrm{ij}} \cdot\left[\mathrm{dt}_{\mathrm{ijk}} /\left(1+\mathrm{t}_{\mathrm{ijk}}\right)\right]
$$

$\varepsilon m_{\mathrm{ij}}$ é a elasticidade-preço da demanda de importações, $\varepsilon m_{i j}=\left(d m_{i j k} k\right.$ $\left.d p_{i j k}\right) \cdot\left(p_{i j k} / m_{i j k}\right)$.

A criação de comércio dá-se quando os países que formam um acordo diminuem suas tarifas, reduzindo a demanda pela produção doméstica de alto custo e aumentando a importação dos países membros do acordo que produzem a custos menores que a produção doméstica. Isso provoca ganhos de bem-estar tanto do lado da produção quanto do consumo. Da mesma forma após as substituições e simplificações a expressão para o desvio de comércio $\left(\mathrm{TD}_{\mathrm{ijk}}\right)$ pode ser expressa como:

$$
T D_{i j k}=\frac{m_{i j k} \cdot m_{i j K} \cdot \varepsilon_{s} \cdot\left(d p r_{i} / p r_{i}\right)}{m_{i j k}+m_{i j K}+m_{i j k} \cdot \varepsilon_{s} \cdot\left(d p r_{i} / p r_{i}\right)}
$$

$\mathrm{dpr}_{\mathrm{i}} / \mathrm{pr}_{\mathrm{i}}$ representa a mudança relativa no preço do bem i dada à

\footnotetext{
${ }^{2} \mathrm{O}$ equivalente ad valorem refere-se às incidências tarifárias, transportes, seguros e fretes, além de outros obstáculos não-tarifários.

${ }^{3}$ Uma descrição completa do processo de derivação das equações para cálculo da criação e desvio de comércio encontra-se em Fonseca (2004).
} 
redução tarifária para os países membros do acordo, $m_{i j K}$ representa a importação do bem i do pais j oriunda de países não membros e $\varepsilon_{s}$ é a elasticidade-substituição de Armington, definida da seguinte forma:

$$
\varepsilon_{s}=\frac{d\left(\sum m_{i j k} / \sum m_{i j K}\right) /\left(\sum m_{i j k} / \sum m_{i j K}\right)}{d\left(P_{i j k} / P_{i j K}\right) /\left(P_{i j k} / P_{i j K}\right)}
$$

O desvio de comércio ocorre a partir da troca de um fornecedor mais eficiente, não membro do bloco, por outro, menos eficiente, porém pertencente ao bloco e que é favorecido pelo diferencial de tarifas externas.

\subsection{Fonte dos dados e descrição do procedimento utilizado}

Os cálculos realizados para a mensuração da criação e o desvio de comércio foram feitos utilizando dados referentes aos principais produtos agrícolas exportáveis brasileiros obtidos junto ao MDIC/SECEX. Foi feita uma compatibilização, para os produtos analisados, entre os setores da Nomenclatura Brasileira de Mercadorias (NBM) e da Nomenclatura Comum do MERCOSUL (NCM), que o Brasil passou a utilizar a partir de 1996, com o objetivo de capturar os efeitos da ALCA sobre os produtos individualizados e não por seções do Sistema Harmonizado (SH).

Os dados sobre as importações totais dos produtos agrícolas dos países membros da ALCA foram obtidos da Organização das Nações Unidas para Agricultura e Alimentação (FAO) (2002). Os dados da FAO são disponibilizados em base anual, expressos em dólares dos Estados Unidos, na condição de compra CIF (Cost, Insurance and Freight) e em toneladas métricas.

Quanto à elasticidade-preço da demanda de importações dos principais produtos agrícolas, foi utilizada uma proxy de acordo com os resultados obtidos por Cline et. al. (1978) para os Estados Unidos. Essas elasticidades dos Estados Unidos possuem valores altos e aparentemente mais condizentes com a realidade brasileira atual, devido a isso se optou pelo seu uso nesse estudo ${ }^{4}$.

Utilizou-se como proxy da elasticidade-preço da demanda de importações o valor $(-0,13)$ para o suco de laranja, o açúcar e o cacau; para

\footnotetext{
${ }^{4}$ As elasticidades obtidas por Cline et.al. (1978) são utilizadas por diversos autores para calcular os prováveis impactos comerciais gerados pela ALCA, ver, por exemplo, os trabalhos de Carvalho e Parente (1999) e Carvalho et. al. (1999).
} 
o café utilizou-se a elasticidade correspondente ao valor $(-0,9)$; para as carnes $(-0,53)$ e para a soja o valor $(-0,43)$, ver Tabela 1 .

Tabela 1 - Elasticidade preço da demanda de importações para os EUA

\begin{tabular}{llc}
\hline Capítulos do $\boldsymbol{S H}$ & \multicolumn{1}{c}{ Descrição } & Elasticidades \\
\hline I a V & Animais vivos e produtos animais & $-0,53$ \\
VI a IX & Produtos vegetais & $-0,9$ \\
X a XIV & Gordura animal, vegetal, óleos e ceras & $-0,43$ \\
XV a XXIV & Gêneros alimentícios preparados, bebidas e fumos & $-0,13$ \\
\hline
\end{tabular}

Fonte: Cline et. al. (1978)

No que se refere à elasticidade de substituição foram utilizadas como proxy os valores obtidos por Tourinho, Kume e Pedroso (2003). O motivo para tanto, foi simplesmente a disponibilidade no uso das elasticidades já calculadas pelos autores para o caso do Brasil.

Assim, para o cálculo do desvio de comércio foi usado como proxy para a elasticidade de substituição o valor $(-0,49)$ para o cacau, o açúcar, e o suco de laranja; para o complexo da soja foi utilizado o valor $(-1,15)$; para as carnes, foi utilizado o valor $(-3,8)$ e para o café $(-2,47)$, ver Tabela 2 .

Tabela 2 - Elasticidades de Armington para o Brasil: 1986-2001

\begin{tabular}{lc}
\hline Capítulos do $\boldsymbol{S H}$ & Elasticidades \\
\hline Abate e preparação de carnes & $-3,80$ \\
Beneficiamento de produtos vegetais e fumo & $-2,47$ \\
Óleos vegetais e Gordura para alimentação & $-1,15$ \\
Outros produtos alimentares e bebidas & $-0,49$ \\
\hline
\end{tabular}

Fonte: Tourinho, Kume e Pedroso (2003)

Quanto às tarifas de importação, foram usados os correspondentes $a d$ valorem das tarifas de importação dos Estados Unidos para os principais produtos agrícolas exportados pelo Brasil e calculados pela Embaixada do Brasil em Washington (2002) e pela United States International Trade Comission (USITC) (2003), ver Tabela 3. Os EUA representam o maior parceiro comercial do Brasil dentro da ALCA, assim suas tarifas de importação serão usadas como proxy para representar as tarifas aplicadas pelos países membros da ALCA. 
Tabela 3 - Equivalente ad valorem para produtos agrícolas de exportação brasileiros

\begin{tabular}{ccc}
\hline TEC $^{1}$ & Descrição & $\%$ \\
\hline 0901.11 .10 & Café & 11,50 \\
1507.10 .00 & Óleo de soja em bruto & 19,70 \\
2009.11 .00 & Suco de laranja concentrado & 44,70 \\
1701.11 .01 & Açúcar em bruto & 20,00 \\
1801.00 .01 & Cacau & 40,00 \\
0201.10 .00 & Carnes $^{2}$ & 10,00 \\
\hline
\end{tabular}

Fonte: Embaixada Brasileira em Washington (2002), United States International Trade Comission - USITC (2003) e SECEX (1999). ${ }^{1}$ TEC (Tarifa externa comum do Mercosul). ${ }^{2}$ Para as carnes o equivalente ad valorem utilizado aqui foi apresentado pela USITC (2003).

O caso do açúcar merece comentários adicionais. Segundo dados da SECEX (2001) o açúcar de cana bruto brasileiro chega a ser tarifado em até $140,30 \%$ no mercado americano, mas o equivalente ad valorem para pode chegar a $236 \%$. Neste trabalho, optou-se pelo equivalente ad valorem obtido junto a USITC (2003) para açúcar em bruto, que é de $20 \%$, pois este valor é cobrado não só nos EUA como também na maioria dos países que fazem parte da ALCA.

Assumindo-se que a produção agrícola brasileira dos principais produtos da pauta de exportação seja competitiva entre os países que formam a ALCA, o modelo proposto em Laird e Yeats (1986) será usado para analisar os fluxos de comércio, entre o Brasil e a ALCA, dos principais produtos agrícolas brasileiros exportáveis entre 1999 e 2002.

\subsection{Os resultados das simulaçóes}

As simulações realizadas admitem a eliminação de $100 \%$ das barreiras comerciais para o fluxo de comércio dos produtos agrícolas brasileiros intrabloco $^{5}$. Os resultados, apresentados na Tabela 4, mostram que um acordo de livre comércio entre o Brasil e os outros países das Américas traria um aumento no volume exportado para todos os produtos agrícolas analisados.

Para todos os produtos analisados, os valores da criação de comércio mostram-se maiores que os valores calculados para o desvio

${ }^{5} \mathrm{O}$ uso da hipótese de desgravação tarifária total é baseado na metodologia desenvolvida por Laird e Yeats (1986) e utilizada em análises posteriores acerca da participação do Brasil na ALCA, como por exemplo, no trabalho de Carvalho e Parente (1999). 
de comércio. Isso significa dizer que, em virtude da formação da ALCA, os países membros substituiriam a produção doméstica pela importação desses produtos oriundos do Brasil. A criação de comércio evidencia a competitividade das exportações brasileiras dessas commodities dentro do bloco.

O café apresenta o aumento mais expressivo no caso dos produtos para os quais a criação de comércio supera o desvio de comércio. Em média, entre 1999 e 2002, 90\% do aumento das exportações brasileiras de café com destino a ALCA ocorreriam em função da criação de comércio. Cerca de $20 \%$ do café exportado no Brasil têm como destino a ALCA e esse aumento significaria que as exportações de café pós-acordo seriam de US\$ 816,85 milhões anuais.

No caso do cacau, após a desgravação, o aumento de $25 \%$ das exportações brasileiras, em média entre 1999-2002, para os países da ALCA dar-se-ia $13 \%$ em função do efeito criação de comércio e $12 \%$ em função do efeito desvio de comércio.

No que se refere ao suco de laranja temos que metade desse produto importado pelos países da ALCA, em média, entre 1999-2002 é de procedência brasileira. Supondo-se a liberalização total das barreiras comerciais, as exportações de suco de laranja apresentariam um aumento médio de $22 \%$, dos quais $13 \%$ seriam fruto da criação de comércio e $9 \%$ do desvio de comércio entre 1999-2002. Por outro lado, a liberalização comercial entre os países membros da ALCA geraria um aumento de $20 \%$ nas exportações do açúcar brasileiro para o bloco, sendo a criação de comércio responsável por $13 \%$ deste aumento.

No caso do complexo da soja, a eliminação das tarifas provocaria um aumento no volume exportado para os países membros da ALCA da ordem de $61 \%$, em média, entre 1999 e 2002, dos quais $43 \%$ ocorreriam em função da criação de comércio e $18 \%$ em função do desvio de comércio. Ainda é pequeno o comércio de soja entre os países membros da ALCA e o Brasil, em média, entre 1999 e 2002 apenas 3 \% de soja importada pela ALCA tinha procedência brasileira. Observe-se que a eliminação tarifária teria gerado um incremento nas exportações brasileiras de US\$ 185,89 milhões, em média, para os países da ALCA entre 1999 e 2002. 


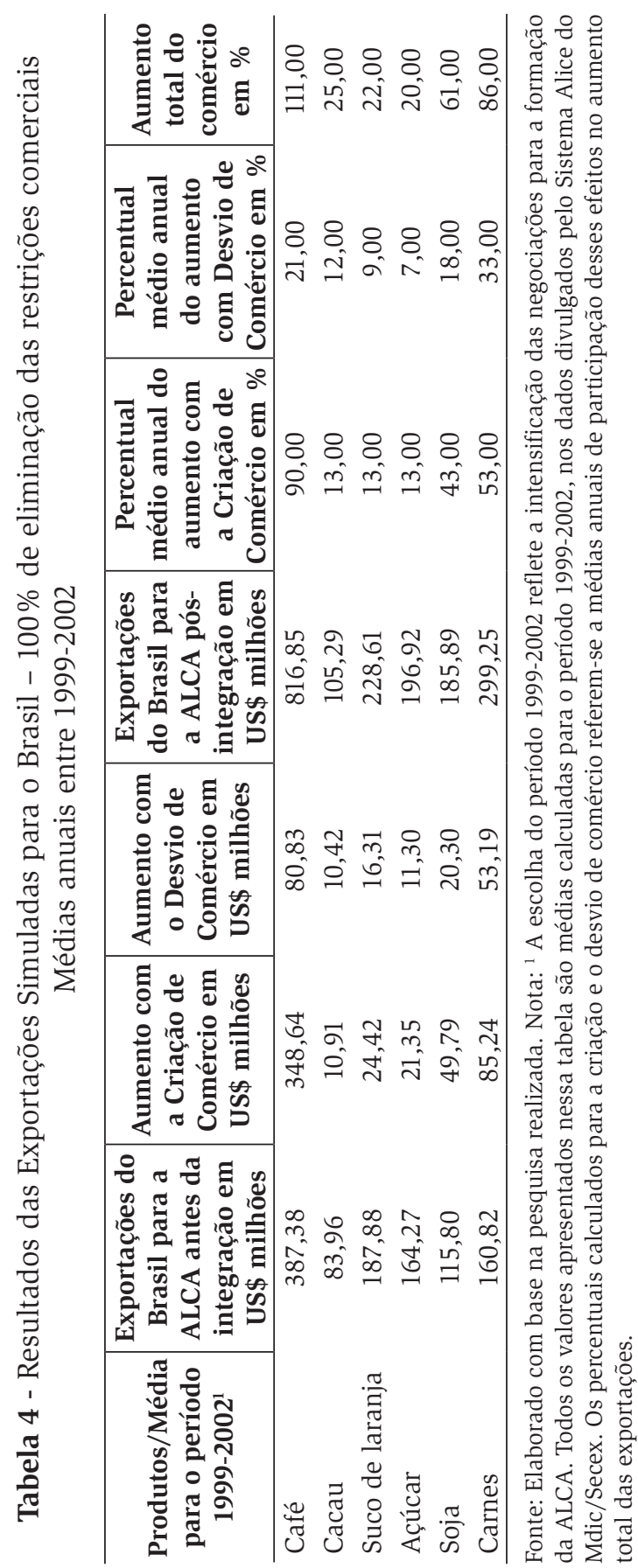

RER, Rio de Janeiro, vol. 44, no 01, p. 009-026, jan/mar 2006 - Impressa em abril 2006 
Alguns autores têm realizado estudos calculando os efeitos da criação e do desvio de comércio para produtos agrícolas exportáveis do Brasil. Dentre eles, Kume (2003), realizou um estudo com o objetivo de quantificar o incremento das exportações e importações brasileiras devido a ALCA, através da simulação de um acordo de livre comércio entre o Brasil e os EUA, com base no modelo de equilíbrio parcial de Laird e Yeats (1986) para o período 1999-2000.

O autor apresentou um levantamento detalhado das restrições nãotarifárias para cada produto, usando os equivalentes tarifários mais apropriados disponíveis na literatura. Os produtos foram apresentados de acordo com as seções do $\mathrm{SH}^{6}$.

Os resultados de Kume (2003) mostram que o Brasil teria vantagem na exportação de 92 produtos, que atingiriam uma venda anual para os Estados Unidos de US\$ 2.201 milhões. Supondo-se a eliminação total das barreiras sobre as importações oriundas do Brasil, os ganhos dessas exportações alcançariam US\$ 1.228 milhões no mercado norte-americano, dos quais $43 \%$ corresponderiam à eliminação das barreiras não-tarifárias e 56,7\% decorrentes da eliminação das tarifas. A eliminação das restrições comerciais causaria um aumento de US\$ 697 milhões nas exportações brasileiras totais para os Estados Unidos, dos quais $34,2 \%$ deste aumento seriam devidos ao açúcar e a produtos contendo açúcar e 13,6\% devido ao suco de laranja. Quanto ao suco de laranja a desgravação geraria um aumento nas exportações para os EUA da ordem de $80 \%$, percentual bastante diferente ao encontrado neste estudo (22\%), como foi mostrado na Tabela 4. Acredita-se que esse fato ocorra em função do uso de diferentes elasticidades-preço da demanda ${ }^{7}$ para os produtos em análise.

Um outro trabalho que pode ser citado é o de Cypriano e Teixeira (2003), que utilizando um modelo de equilíbrio geral computável (GTAP), realiza estudo com o objetivo de determinar os impactos da criação de áreas de livre comércio em que se eliminam as tarifas sobre importações, envolvendo os países da ALCA no setor do agronegócio, e do MERCO-

\footnotetext{
${ }^{6}$ A maioria dos trabalhos até então realizados, acerca dos efeitos sobre o comércio de produtos agrícolas exportáveis, em virtude da participação do Brasil na ALCA tem utilizado a desagregação proposta pelos capítulos do SH, não particularizando os produtos individualmente, como é o caso do presente estudo.

${ }^{7}$ Kume (2003) usa as elasticidades calculadas por Hoekman, Ng e Olarreaga (2002), que variam de $(-0,4)$ a $(-2,35)$, sendo especialmente no caso do suco de laranja, um valor bastante inferior ao obtido por Cline et. al. (1978) e usado no presente estudo.
} 
SUL com a União Européia, na perspectiva de extinção dos subsídios à produção e à exportação. Os autores encontraram para o açúcar um incremento nas exportações da ordem de $23,05 \%$ para o ano de 1997 . A Tabela 4 mostra que as exportações de açúcar brasileiro em função da formação da ALCA, caso ocorresse desgravação total, aumentariam em média $20 \%$ entre 1999 e 2002. Esse valor é bastante aproximado ao de Cypriano e Teixeira (2003) mesmo aqui sendo utilizada uma metodologia diferente, ou seja, uma análise de equilíbrio parcial.

\section{Conclusão}

A década de 90, além da abertura comercial brasileira, foi marcada pelas experiências de participação no MERCOSUL e as negociações para a formação da ALCA. Ambas tiveram uma grande importância sobre o mercado agrícola brasileiro e o processo de integração regional trouxe ao Brasil a ampliação do mercado assim como um incentivo maior à exportação de commodities.

A formação da ALCA vem gerando grandes expectativas nos exportadores de produtos agrícolas brasileiros graças à possibilidade de ampliação de seus mercados. Os resultados das simulações feitas neste trabalho só corroboram o que outros autores têm encontrado mesmo que a partir de metodologias diferentes.

A simulação da eliminação de $100 \%$ das restrições comerciais, em média entre, 1999-2002, mostrou um crescimento do volume exportado de café brasileiro para a ALCA de $111 \%$, para o cacau de $25 \%$, para o suco de laranja de $22 \%$, para o açúcar de $20 \%$, para a soja de $61 \%$ e para as carnes de $86 \%$. Em todos os casos o efeito criação de comércio supera o efeito desvio de comércio tornando evidente a competitividade dessas exportações dentro da ALCA.

Caso o bloco seja formado, esse estudo mostra que ocorrerá um aumento das exportações agrícolas brasileiras no que tange a esse grupo de produtos. Um aumento no volume das exportações agrícolas brasileiras para seus parceiros, após a desgravação tarifária, acarretará uma redução dos preços dos produtos dentro dos mercados compradores. Admitindose que os produtos brasileiros sejam competitivos, a substituição por um comprador eficiente evidencia criação de comércio para tais produtos. 
Tendo em vista este aspecto, o setor agrícola exportador brasileiro não só espera que a criação da ALCA promova a eliminação de barreiras alfandegárias, quotas, barreiras tarifárias e barreiras sanitárias e fitossanitárias que hoje impedem o acesso e a expansão da produção brasileira ao mercado americano, como também espera a imposição de limitações mais fortes que as praticadas no âmbito da $\mathrm{OMC}$, no que diz respeito à utilização de subsídios pelos EUA e Canadá para a produção agrícola.

Os resultados aqui apresentados demonstram a necessidade de dentro das negociações da ALCA, o Brasil lutar por uma liberalização do comércio agrícola em bases recíprocas, no que diz respeito à desregulamentação dos mercados, aprimoramento das regras sobre antidumping e medidas de salvaguarda, combate ao protecionismo sanitário e redução principalmente de barreiras não-tarifárias.

\section{Referências bibliográficas}

ABREU, Marcelo de Paiva. Política comercial brasileira: limites e oportunidades. Rio de Janeiro: PUC, 2001. p.1-22. (Texto para discussão, 457).

CARVALHO, Alexandre; PARENTE, Maria Andréia. Impactos comerciais da Área de Livre Comércio das Américas. Brasília: IPEA, 1999. (Texto para Discussão, 635).

CARVALHO, Alexandre; PARENTE, Maria Andréia; LERDA, Sandra; MIYATA, Shiyuiti. Impactos da integração comercial Brasil-EUA. Brasília: IPEA, 1999. (Texto para Discussão, 646).

CLINE, R. W.; KAWANABE, N.; KRONSJO, T.M. Trade Negotiations in the Tokyo round: a quantitative assessment. Washington: The Brookings Institution, 1978.

CYPRIANO, Luiz Alberto; TEIXEIRA, Erly. Impactos da ALCA e MERCOEURO no Agronegócio do MERCOSUL. Revista da SOBER, v.41, n.2, abr./jun. 2003, p. 217-238.

DE NEGRI, J. Alberto; ARBACHE, Jorge Saba; SILVA, Maria L. F. A formação da ALCA e seu impacto no potencial exportador brasileiro para os mercados dos Estados Unidos e Canadá. Brasília : IPEA, 2003, 36 p. (Texto para discussão, 991).

EMBAIXADA DO BRASIL. Barreiras aos produtos e serviços brasileiros no mercado norte-americano. Washington, 2002. 
FAO - Food and Agriculture Organization of the United Nations. Desenvolvido por webmaster@fao.org, 1990.

FONSECA, M. B. Abertura Comercial e Integração Regional: impactos da ALCA sobre as exportações agrícolas brasileiras numa abordagem de equilíbrio parcial. 2004. 198f. Tese (Doutorado em Economia) - Universidade Federal de Pernambuco, Recife, 2004.

HOEKMAN, Bernard; NG, Francis; OLARREAGA, Marcelo. Reducing agricultural versus domestic support: what's more important for developing countries? World Bank Policy Research, Washington, USA, 2002 (Working Papers, 2918).

KUME, H. ALCA: uma estimativa do impacto no comércio bilateral BrasilEUA. XXXI Encontro Nacional da ANPEC, 2003.

LAIRD, S.; YEATS, A. The UNCTAD trade policy simulation model: a note on the methodology, data and uses. Geneva: UNCTAD, 1986. (Discussion Papers, 19).

MINISTÉRIO do Desenvolvimento, Indústria e Comércio Exterior - Secretaria de Comércio Exterior (MDIC/SECEX). Disponível em: < http://www.aliceweb. desenvolvimento.gov.br > . Acesso em: nov./nov. 2002-2004.

OMC - Organização Mundial de Comércio. Desenvolvido por enquires@wto. org. Disponível em: < http://www.omc.com > . Acesso em: 22 jul. 2004.

SECEX, Barreiras Externas às Exportações brasileiras para os EUA, Japão e União Européia, [on line], 2001, 53p.

TAVARES, Carlos Eduardo Cruz. Soja. Disponível em: < http://www.conab. gov.br > . Acesso em: 05 dez. 2002.

TOURINHO; Otávio, KUME; Honório; PEDROSO, Ana Cristina. Elasticidades de Armington para o Brasil - 1986-2002: novas estimativas. Rio de Janeiro: IPEA, 2003, 21p. (Texto para Discussão, 974).

USITC - United States International Trade Comission. Desenvolvido por webmaster@usitc.gov, 2003. Disponível em: < http://www.usitc> .

VALVERDE, Sebastião; TEIXEIRA, Erly. Impactos do Acordo da Área de Livre Comércio das Américas (ALCA) no comércio internacional. In: CONGRESSO BRASILEIRO DE ECONOMIA E SOCIOLOGIA RURAL, 30, 1997, Natal: SOBER, 1997. 1 CD-ROM.

Recebido em setembro de 2004 e revisto em novembro de 2005 